\title{
Los estudios sobre el conflicto armado y la construcción de paz en Colombia desde una perspectiva territorial: abordajes y desafíos ${ }^{*}$
}

DOI: https://doi.org/10.18046/recs.i33.3995

\section{Studies on the Armed Conflict and the Peace Building in Colombia from a Territorial Perspective: Approaches and Challenges}

\author{
Cristian Rojas-Granada ${ }^{* *}$ \\ Universidad de Caldas (Manizales, Colombia)
}

Reinaldo Cuesta-Borja ${ }^{* * *}$

Universidad Tecnológica del Chocó (Quibdó, Colombia)

\footnotetext{
* Este artículo es producto de las investigaciones doctorales de los autores en el Doctorado en Estudios Territoriales de la Universidad de Caldas (Colombia), a través del programa de investigación Reconstrucción del Tejido Social en Zonas de Posconflicto en Colombia (Código SIGP: 57579) y el proyecto de investigación Hilando Capacidades Políticas para las Transiciones en los Territorios (Código SIGP: 57729), financiados en el marco de la convocatoria Colombia Científica (Contrato núm. FP44842-2132018). Artículo de revisión recibido el 27.04.2020 y aceptado el 03.01.2021.

** Antropólogo, magíster en Ciencias Sociales, estudiante del Doctorado en Estudios Territoriales de la Universidad de Caldas (Colombia) y docente investigador de la misma universidad. Correo electrónico: cristian.rojas@ucaldas.edu.co. ORCID: https://orcid.org/0000-0001-9190-2664

*** Administrador de empresas, magíster en Gobierno y Políticas Públicas, estudiante del Doctorado en Estudios Territoriales de la Universidad de Caldas (Colombia) y profesor asociado de la Universidad Tecnológica del Chocó (Colombia). Correo electrónico: d-reinaldo.cuesta@utch.edu.co. ORCID: https://orcid.org/0000-0002-9911-7801
} 


\section{Cómo citar/How to cite}

Rojas-Granada, Cristian; Cuesta-Borja, Reinaldo (2021). Los estudios sobre el conflicto armado y la construcción de paz en Colombia desde una perspectiva territorial: abordajes y desafíos. Revista CS, 33, 205-235. https://doi.org/10.18046/recs.i33.3995 


\section{Resumen}

El artículo presenta un análisis crítico de la literatura reciente sobre conflicto armado y construcción de paz en el contexto colombiano desde una perspectiva territorial. Se consultaron bases de datos de revistas científicas a partir de la combinación de las palabras territorio, conflicto armado y paz, incluyendo material desde 2008. Se encontró que este tipo de estudios han abordado la dimensión simbólica del territorio para analizar aspectos como el desplazamiento forzado, las resistencias territoriales en contextos de conflicto armado que se constituyen como iniciativas de paz desde las comunidades afectadas por la violencia y el estudio de las transformaciones territoriales producidas por el conflicto armado. Se identificaron investigaciones que se ocupan del análisis de la gestión territorial con relación al conflicto armado y como herramienta importante para la construcción de paz. Se concluye puntualizando los desafíos que, actualmente, dejan abiertos los estudios en este campo.

\section{PALABRAS CLAVE:}

territorio, conflicto, resistencias territoriales, paz territorial, gestión territorial

This paper presents a critical analysis of the recent literature on the armed conflict and the peace building in the Colombian context; from a territorial perspective. Scientific journal databases were consulted, using a combination of the words territory, armed conflict, and peace; the results since 2008 were considered for the analysis. It was found that this type of studies has addressed the symbolic dimension of territory to analyze aspects such as forced displacement, territorial resistance in contexts of armed conflict, which were created to be peace initiatives by the communities affected by violence, and the study of the territorial transformations produced by the armed conflict. The study identified pieces of research focused on the analysis of territorial management in relation to the armed conflict and as an important tool for peace building. This paper concludes by highlighting the challenges revealed by the studies in this field in the current context.

\section{KEYWORDS:}

Territory, Conflict, Territorial Resistance, Territorialization of Peace, Territorial Management 



\section{Introducción}

Este artículo surge en el marco del proyecto de investigación "Hilando capacidades políticas para las transiciones en los territorios", el cual tiene lugar en los departamentos de Sucre, Chocó y Caldas, y busca potencializar las capacidades políticas de algunas de las comunidades más fuertemente afectadas por el conflicto armado en Colombia. Entre las categorías principales de la investigación está el territorio, y de ahí el interés por indagar sobre los enfoques y debates que existen en los estudios recientes para abordar el tema del conflicto armado y la construcción de paz asociados al territorio como categoría de análisis.

La realidad colombiana se ha transformado enormemente en los últimos años. Luego de la firma del acuerdo de paz entre el Gobierno nacional y la guerrilla de las FARC-EP ${ }^{1}$, en el año 2016, disminuyeron algunas formas de violencia en regiones de especial influencia de la antigua guerrilla; sin embargo, en muchos territorios la guerra se ha reconfigurado con nuevos actores que entraron a disputarse el control sobre recursos naturales o de cultivos de coca, lo que evidencia que estamos viviendo un período de posacuerdo con características muy disímiles en las distintas regiones del país (Ávila, 2019; Salas; Wolff; Camelo, 2018). De ahíla necesidad de comprender la producción de conocimiento sobre conflicto y paz desde una perspectiva territorial, con el objetivo de poder aportar a los desafíos que enfrenta el país y sus regiones, para salir de manera definitiva de la guerra.

En el plano conceptual, entendemos que los conflictos son connaturales al ser humano e incluso son necesarios para generar transformaciones que pueden ser favorables para una sociedad (Coser, 1970; Lederach, 2000). La paz no es la mera ausencia de violencia, sino una construcción permanente y siempre imperfecta, en la cual, para su abordaje, es preciso tener en cuenta diferentes aspectos sociohistóricos, culturales y estructurales en cada sociedad (Galtung, 1969; Muñoz; Bolaños, 2011). Asimismo, entendemos que el territorio es una construcción relacional geosociohistórica, multiescalar, producto y productora de sociedad, con dimensiones políticas, económicas, culturales y sociales (Cairo, 2013; Capel, 2016; Llanos, 2010; Nates, 2011). En este sentido, el conflicto armado, las resistencias y las iniciativas de paz son productoras de territorio cuando se tienen en cuenta, por un lado, el complejo de relaciones sociales de naturaleza conflictiva o solidaria que constituyen consuetudinariamente cada territorio y, por otro lado, los aspectos relacionados con

1. Las Fuerzas Armadas Revolucionarias de Colombia-Ejército del Pueblo, luego de la firma del acuerdo de paz, pasan a constituirse como partido político adoptando la misma sigla, pero con el nombre de Fuerza Alternativa Revolucionaria del Común. En una asamblea del año 2021, decidieron cambiar el nombre del partido por Comunes, con el fin de desligarse del anterior, que solía asociarse con su pasado bélico. 
el conflicto armado que, desde la escala nacional y global, impactan de distintas formas los contextos locales, en sus órdenes físico-espacial y simbólico-cultural (Rico; López, 2017). Es por esto que una de las motivaciones para la elaboración de este artículo se encuentra en la tesis de que el conflicto armado y las resistencias pacíficas de las comunidades en Colombia deben ser leídas en clave territorial, teniendo en cuenta la complejidad sociohistórica, cultural y política de cada contexto.

De acuerdo con lo anterior, en las páginas siguientes se exponen los resultados de la revisión crítica de los estudios que se han realizado en los últimos años en Colombia sobre conflicto armado y construcción de paz desde una perspectiva territorial, con el fin de aportar a una mejor comprensión del conflicto armado e identificar las pistas que ofrece el análisis territorial para enfrentar los desafíos que se presentan, actualmente, para construir paz en nuestro país.

\section{Metodología}

Para identificar la literatura publicada sobre conflicto y paz desde una perspectiva territorial, se consultaron bases de datos especializadas de revistas científicas ${ }^{2} \mathrm{y}$, por considerarse de relevancia para el tema, se indagó en los informes del Centro Nacional de Memoria Histórica (CNMH) que hacían mayor alusión a lo territorial a nivel conceptual y metodológico, al igual que otra bibliografía de institutos que se han ocupado de difundir reflexiones teóricas y empíricas sobre los temas de interés de este artículo ${ }^{3}$. El rango de tiempo que se cubrió en la búsqueda fue del año 2008 al 2020, excepto algunos casos en los que se incluyeron documentos publicados en años anteriores por considerarse que su aporte es de especial relevancia.

Se seleccionaron artículos que abordaron el tema del conflicto y la construcción de paz, y que asumieron el territorio como categoría central para sus análisis, entendiéndolo no solo como una ubicación espacial, sino como una construcción resultante de los distintos tipos de relaciones sociales e históricas en cada contex-

2. Las bases de datos consultadas fueron: JStore, Science Direct, Scopus, Web of Science, y otras bases de datos de acceso libre como Scielo, Redalyc y la biblioteca de CLACSO.

3. Fue el caso de publicaciones de centros e institutos de gran tradición en temas de conflicto y paz como el Centro de Investigación y Educación Popular (CINEP), Friedrich Ebert Stiftung (FES), Instituto Colombo-Alemán para la Paz (CAPAZ), y Observatorio Colombiano para el Desarrollo Integral, la Convivencia Ciudadana y el Fortalecimiento Institucional en Regiones Fuertemente Afectadas por el Conflicto Armado (ODECOFI). 
to $^{4} \mathrm{y}$, desde esa concepción del territorio, estudiaron los fenómenos asociados al conflicto armado y la paz. La alusión al territorio debía ser explícito en el mismo título del artículo, en las palabras clave, en el resumen o en los referentes teóricos que le dieran esta connotación de análisis territorial. Los artículos que no contaban con estos criterios fueron excluidos. Todos los artículos analizados son de estudios desarrollados en Colombia. Se incluyeron artículos en lengua castellana e inglés, publicados en revistas colombianas y de otros países.

De la anterior búsqueda, se realizó un metaanálisis con la herramienta bibliometrix ${ }^{5}$, a partir del cual se logró establecer un incremento significativo en la producción científica, a partir del año 2015, sobre territorio, conflicto y paz, haciéndose cada vez más fuertes palabras clave como Colombia, peace building, peace process o peace agreement, temas que coinciden con el hecho de que en esos años se estaba dando el proceso de paz entre el Gobierno nacional de Colombia y las FARC-EP (firmado finalmente en noviembre de 2016), desplazando al conflicto armado, que era la categoría predominante durante los años precedentes. Esto muestra la expectativa del mundo académico con el acuerdo de paz y su implementación.

Se analizaron más de 60 documentos, los cuales fueron clasificados en los siguientes temas: artículos que realizan un énfasis en la dimensión simbólica del territorio para estudiar el conflicto y la paz; otros que abordan las resistencias y transformaciones territoriales en el marco del conflicto y la paz; finalmente, la gestión territorial que permite plantear una mirada crítica tanto a los orígenes del conflicto armado en Colombia como a las dificultades que se han evidenciado en la implementación de los acuerdos de paz, en el plano del ordenamiento territorial y las formas de participación de las distintas comunidades.

4. Ver al respecto el giro espacial en ciencias sociales en Soja (2010) -que desde una perspectiva francófona y latinoamericana se entendería más como giro territorial-, caracterizado por el protagonismo que, desde distintas disciplinas de las ciencias sociales, se le empezó a dar a lo espacial (además de lo temporal que, para entonces, ya tenía un mayor reconocimiento), para la elaboración de análisis sociales, a partir de las décadas de 1980 y 1990.

5. Herramienta de análisis estadístico multivariado a partir de los metadatos de los artículos que se encuentran en las bases de datos y con lo que se pueden establecer tendencias a partir de distintos criterios. Para ampliar al respecto, ver: Aria y Cuccurullo (2017). 


\section{Hallazgos}

\section{Métodos territoriales para el estudio del conflicto y la paz}

La mayoría de los artículos analizados aplicaron métodos y técnicas genéricas de las ciencias sociales (etnografía, entrevistas, diseños mixtos, entre otros) en sus investigaciones; sin embargo, algunos aportan ideas metodológicas novedosas para lo específico de un análisis territorial del conflicto y la paz. Existen algunos métodos y técnicas que se han posicionado tradicionalmente como idóneos para el estudio de lo territorial, como son la cartografía social (Vélez; Rátiva; Varela, 2012) o la cartografía física y sonora (Tamayo; Navarro, 2017), pero asociadas al tema del conflicto armado, esas técnicas suelen combinarse, por ejemplo, con líneas de tiempo que permiten indagar en la memoria individual y social de los participantes (CNMH, 2015). En este último caso, se parte de la conceptualización de un sujeto colectivo directamente ligado al territorio, el campesino, lo cual implica que, para comprender sus características y las de los daños que sufrieron en medio del conflicto armado, se precisa la utilización de técnicas participativas que aborden temas como la producción económica y los circuitos de comercialización, la adjudicación y titulación de tierras, la influencia y localización de los procesos organizativos en tiempos presentes y pasados, entre otros, que brindan una propuesta metodológica potente para el trabajo de memoria desde una perspectiva territorial.

Algunos estudios presentan abordajes metodológicos que usan la cartografía para representar gráficamente los fenómenos de violencia, conflicto y paz (Nates; Raymond, 2006; Ocampo; Chenut; Férguson; Martínez, 2017; Pissoat; Gouëset, 2002). Con los mapas, se busca sintetizar información a partir de indicadores y variables cualitativos y cuantitativos, son herramientas de apoyo gráfico para los análisis de los investigadores sociales y recursos pedagógicos para comunicar de forma eficiente esos análisis a distintos públicos, en un lenguaje visual que complementa al oral o escrito. En cuanto representación, el mapa siempre muestra a la vez que oculta información, lo que refleja las posiciones teóricas y políticas del investigador y de quien lo interpreta posteriormente (Pissoat; Gouëset, 2002; Vélez et al., 2012). Así, por ejemplo, si se entiende la paz como ausencia de violencia o como condiciones estructurales de bienestar para la población, los indicadores y recursos gráficos de un mapa van a ser distintos.

Las representaciones del conflicto armado y las iniciativas de paz plasmadas cartográficamente en los estudios analizados en este artículo evidencian mapas temáticos, que se ocupan de una sola variable, y sintéticos, que entrecruzan varias dimensiones y correlacionan fenómenos de distintas temporalidades (Nates; Ray- 
mond, 2006). Frente a los primeros, suelen ser mapas que muestran la presencia o ausencia de determinado fenómeno en el espacio, como la presencia de un grupo armado o de cultivos de coca en una zona en un momento específico. De acuerdo con el análisis de Pissoat y Gouëset (2002), estos mapas predominaron en la producción científica nacional hasta la década de 1990, cuando se empezaron a tener mejores fuentes estadísticas y se inició el uso de mapas cada vez más complejos, incluso a escala regional y local (lo cual no indica que los mapas temáticos no se sigan utilizando). Por su parte, los mapas sintéticos son cada vez más frecuentes, y muestran la representación espacial de distintas variables que hacen evidente su correlación, como es el caso de la pobreza y un mayor índice de homicidios, o la presencia del paramilitarismo en las zonas de mayor despojo de tierras en ciertas regiones del país en distintas temporalidades (Pissoat; Gouëset, 2002), solo por mencionar dos ejemplos ilustrativos. Sea cual sea el tipo de mapa, su construcción requiere rigor en el uso de fuentes y una interpretación y análisis complejos para evitar reduccionismos o el riesgo de poner en la misma categoría procesos diferentes, como los homicidios que pueden ser por causas políticas o comunes, pero si se unifican pueden generar conclusiones engañosas.

Con la ayuda de los recursos gráficos propios de la cartografía, los investigadores sociales del conflicto y la paz utilizan formas geométricas o simbólicas, colores, íconos y líneas, entre otros, para representar sus hallazgos mediante mapas. A modo de ejemplo, un fenómeno frecuentemente representado a través de esta herramienta es el desplazamiento forzado: normalmente se utilizan flechas que muestran la expulsión de la población de un lugar y su recepción en otro (Nates; Raymond, 2006; Ocampo et al., 2017; Pissoat; Gouëset, 2002).

Este y otros recursos permiten ilustrar gráficamente fenómenos de desterritorialización/territorialización de las comunidades en distintos tiempos y espacios, importantes para el análisis territorial del conflicto armado y sus impactos en la sociedad civil (aspecto que se amplía en los siguientes apartados de este artículo). Desde una perspectiva participativa, Vélez, Rátiva y Varela (2012) utilizaron la cartografía social para construir mapas conjuntamente con los pobladores de un corregimiento del norte del Cauca, ejercicio que les permitió establecer fronteras que dan cuenta de procesos de alteridad que son producto de territorialidades en disputa -al identificar comunidades, actores sociales o institucionales con las cuales un grupo marca diferencias o conflictos, frente otras con las cuales sostiene solidaridades o complicidades-. Los autores señalan que la cartografía social y los productos que de ella emanan deben ser útiles para las reivindicaciones, exigencias y luchas sociales de las comunidades frente al Estado o empresas que llegan a sus territorios con interés de generar allí algún tipo de impacto. 
También el trabajo etnográfico de Espinosa, González y Ramírez (2012) presenta elementos útiles para cualquier investigador que se enfrenta a desarrollar su trabajo de campo en contextos de conflicto armado, como contar siempre con una carta de presentación institucional - de la Defensoría del pueblo- y contar con números de contacto de personas locales. Aspectos de protección del investigador que se complementan con otros que buscan proteger a los lugareños, como saber identificar qué se puede decir y qué no se puede decir en determinados contextos socioespaciales, a lo que se le suma el saber leer los silencios y procurar rigurosidad al guardar la confidencialidad de la información que se obtenga en campo.

Otra propuesta etnográfica, con un interés explícito en el desarrollo metodológico sobre el tema que se discute en este artículo, es la etnografía territorial propuesta por Nates, Velázquez y García (2017), la cual busca que el ejercicio etnográfico haga del lugar su foco de análisis, no entendido como un contenedor, sino como una construcción resultante de la red de relaciones sociales que le otorgan sentido y de la cual entra a hacer parte el mismo investigador. Por su parte, desde la geografía se presenta la propuesta metodológica de la geografía de performance (Courtheyn, 2019), que consiste en que el investigador haga parte activa de las prácticas corporalizadasy espaciales en terreno con las comunidades, desde una perspectiva crítica y de investigación comprometida.

De acuerdo con lo anterior, se puede afirmar, en términos generales, que, si bien se brindan algunas pistas metodológicas por parte de los investigadores, el campo de reflexión método-lógica del análisis territorial del conflicto y la paz sigue siendo un campo fértil al cual se puede seguir contribuyendo, con el fin de brindarle más y mejores herramientas a la comunidad académica interesada en el estudio del conflicto y la paz desde una perspectiva territorial.

\section{Abordajes del conflicto y la paz desde la significación del territorio}

Una parte de las investigaciones encontradas se ocupan de la dimensión simbólica del territorio para estudiar fenómenos de conflicto y de paz. En este apartado, se agruparon las investigaciones que hablan de los valores asociados al territorio, entendidos como territorialidad (Monnet, 2013) o como significados, imaginarios o representaciones del territorio. Como veremos a continuación, algunos estudios enfatizan más en los significados, otros en las prácticas cotidianas asociadas a esos significados, y los demás hacen mayor énfasis en las acciones colectivas que por iniciativa de las comunidades buscan dotar de nuevos significados a sus propios territorios antes marcados por la violencia. 
Chávez y Ramírez (2018) abordaron el territorio como el objeto de las representaciones sociales (desde la psicología social de Moscovisci) que un grupo de mujeres del sector rural de Cundinamarca, en el centro del país, construyeron a partir de los acuerdos de paz de 2016. Encontraron que esas mujeres contaban con representaciones negativas y positivas sobre su territorio, relacionadas con aspectos como las condiciones de seguridad, las limitaciones económicas del campo y el sentido de pertenencia que tienen por su municipio. En un sentido similar, Ospina, López, Burgos y Madera (2018) indagaron en los imaginarios sobre la paz que tenían algunos niños de una ciudad del centro del país como Manizales, y otros del sector rural del departamento del Cauca, y encontraron que para los niños de la ciudad la paz está asociada a imágenes de naturaleza como bosques y playas, mientras que para los niños del campo está más asociada a ideas de desarrollo en infraestructura, porque imaginan calles y edificios en su territorio rural para representar la paz.

Para el caso de la comunidad de los Llanos del Yarí, al sur del país, el significado que le atribuyen al territorio está ligado a su historia de violencia y resistencia, a partir de la cual se han creado fronteras simbólicas adscritas a una identidad política de un nosotros-dentro que contraste con un otros-fuera, lo que refleja la cohesión e identificación de la comunidad con su territorio, al tiempo que desconfían de quienes se ubican fuera de él, sea el mismo Estado o los actores armados (Espinosa et al., 2012). Este análisis coincide con el de Lizarralde (2012) en su estudio sobre los territorios del miedo en una escuela rural del Putumayo, en el sur del país, en el cual se expone cómo la forma de relacionarse con el territorio de toda la comunidad educativa ha estado mediada por el miedo y la desconfianza como consecuencias del conflicto armado.

Ocampo et al. (2017), inspirados en Monnet (2013), entienden la territorialidad como la relación material y simbólica que se tiene con el territorio, el cual se construye a partir de las prácticas cotidianas. Con base en este precepto, indagaron cómo esa territorialidad cambió en distintas poblaciones desplazadas por el conflicto interno armado en Colombia (campesinos, mujeres y comunidades étnicas), durante la transición de pasar de vivir en el campo a construir su nuevo lugar en distintas ciudades, donde deben establecer nuevas relaciones y nuevas prácticas acordes con las condiciones de la vida citadina que van dando forma a la nueva territorialidad en el lugar de destino; y encontraron que el significado que el desplazado le otorga a la ciudad mejora en la medida en que alcanza condiciones de vida satisfactorias para él y su familia en lo relacionado, por ejemplo, con acceso a vivienda y empleo.

Adicional a lo anterior, Motta (2009) subraya que ese proceso de transición y construcción de nuevos significados sobre el territorio urbano al cual llegan los 
desplazados se vive de forma distinta según el género, la etnia, la edad y el lugar de origen de cada persona. Además, estudios como los de Garzón (2008) y Tamayo y Navarro (2017) muestran cómo desde las mismas comunidades surgen iniciativas para dotar de significados diferentes a sus territorios, luego de que fueran marcados por la violencia y el miedo. En el primer caso, se muestra la experiencia de lo que los autores denominan ciudadanías comunicativas -en el sector rural de la ciudad de Medellín- y que se entienden como la capacidad colectiva de los ciudadanos para expresar sus demandas o reivindicaciones sociales a través de acciones simbólicas en la esfera pública, en contextos culturales marcados por el conflicto armado, con el fin de salvaguardar la memoria de las víctimas y denunciar las injusticias (Tamayo; Navarro, 2017).

El otro caso es analizado por Garzón (2008), con la experiencia de un cineclub itinerante en Montes de María (región Caribe), a partir de lo que la autora denomina las políticas del lugar, entendidas como la forma que tienen las comunidades para recuperar espacios que habían sido violentados o prohibidos por los grupos armados; es decir, el cineclub itinerante como una forma colectiva de territorializar produciendo lugares con un nuevo significado para la comunidad, ya no vinculado a la violencia, sino a la vida y la paz. En estos dos estudios se asume que la transformación del significado del territorio también implica la resignificación de las identidades de las mismas comunidades que lo habitan.

De acuerdo con lo anterior, el territorio se ha estudiado desde su dimensión simbólica y se establece cómo distintos sujetos o comunidades, según sus experiencias y orígenes, le otorgan un significado particular a este, como el caso de los desplazados por la violencia-las mujeres o los niños en sectores rurales o urbanos-, mientras que otros estudios abordan contextos donde las personas se resisten a las imposiciones de los violentos y disputan los significados sobre su territorio a través de acciones colectivas simbólicas y situadas.

\section{Formas de resistencia territorial en el marco del conflicto armado}

La ontología política (Escobar, 2015) es un concepto que sirve para señalar que, para algunas comunidades, la concepción del territorio es radicalmente diferente a la propia de la cultura occidental moderna y capitalista, para la cual la realidad se entiende a partir de dicotomías que, por ejemplo, separan al ser humano de la naturaleza, lo que conduce a una relación instrumental con esta última (Courtheyn, 2019). En contraste, para el caso de algunas comunidades indígenas, en el territorio se articulan lo cotidiano y lo sagrado, y no hay una separación tan tajante entre este y los seres humanos o no humanos (Cuesta, 2018). Algo similar ocurre con algunas comunidades afro, para quienes el territorio se concibe como un ser vivo, parte indispensable de sus 
vidas para producir y recrearse como comunidad (Courtheyn, 2019). Incluso, esto ha permitido que la misma legislación colombiana haya reconocido al territorio como víctima del conflicto armado, como sujeto de derechos (Ruiz, 2017), no solo por lo relacionado con lo ambiental (como los impactos negativos de los cultivos ilícitos, minería ilegal o derrame de petróleo en los ríos), sino también porque el conflicto violentó el sentido sagrado y vital que tiene el territorio para las comunidades.

Lo anterior ha derivado en unas territorialidades en disputa entre las comunidades para quienes el territorio es un ser vivo (Courtheyn, 2019) o la madre tierra (Cuesta, 2018; Ocampo et al., 2017), y la visión utilitarista sobre el territorio, propia de los grupos armados o de las políticas neoliberales y extractivistas materializadas en los contextos locales a través de las políticas del Estado (Courtheyn, 2019). La experiencia de la Comunidad de Paz de San José de Apartadó es un ejemplo de una comunidad que resiste y territorializa de forma pacífica a través de actos conmemorativos, marchas y redes productivas y solidarias que constituyen un territorio de paz, en cuya concepción se encuentra implicada la resistencia, pues entiende la paz como "una práctica diaria de trabajo colectivo, guiada por valores anti-capitalistas y anti-individualistas" (Courtheyn, 2019:302).

Esta experiencia de resistencia territorial es retomada por un completo análisis de las territorialidades en disputa en el Urabá antioqueño (García de la Torre; Aramburo-Siegert, 2011), donde se advierte que la Comunidad de Paz aportó a la construcción del territorio al tramitar y mediar las conflictividades entre las territorialidades armadas y las territorialidades socioculturales de las comunidades afectadas. Las autoras coinciden con Echandía y Cabrera (2017) en tomar la definición de territorialidad de Sacks, para referirse al sentimiento de pertenencia, es decir, a aquellos modos de comportamiento y control de un área geográfica específica que incluyen el conjunto de prácticas materiales y simbólicas mediante las cuales un determinado agente garantiza su apropiación y permanencia en un territorio específico, un proceso que delimita el territorio en divisiones espaciotemporales y, finalmente, genera una conducta por medio de la cual un actor busca influir o afectar un territorio particular.

De acuerdo con lo anterior, las territorialidades en contextos de guerra hacen referencia a que los actores armados adelantan esfuerzos de influencia y control sobre personas, recursos y relaciones sociales en un espacio delimitado, por medio del uso potencial o directo de acciones coercitivas o de violencia, con lo cual emerge la categoría de territorialidad armada, para hacer referencia a las actividades de grupos armados en los territorios ${ }^{6}$. De esta manera, el componente de control de un área geográfica es más restringido en las territorialidades socioculturales que en las

6. Esta categoría difiere de la idea de territorialidad que se mostró previamente en este artículo, ligada fundamentalmente a los valores asociados al territorio. 
bélicas o empresariales; sin embargo, algunas comunidades, como la de San José de Apartadó, han mostrado su capacidad de organización social para resistir a las territorialidades armadas. En un sentido muy cercano está el concepto de territorialidad contra-hegemónica, entendida como los procesos que surgen desde las mismas comunidades para enfrentar el acecho del neoliberalismo sobre sus territorios, y que pasa por reconocer los saberes y prácticas colectivas subestimadas por la ideología capitalista (Bautista, 2017).

A su vez, las comunidades indígenas del norte del departamento del Cauca han realizado procesos pacíficos de defensa de su territorio frente a los actores armados (legales e ilegales), pues consideran que su presencia, incluida la fuerza pública, les trae inseguridad y desarmoniza su territorio ancestral (Peña, 2019; Uribe; Ramírez, 2014). Otra experiencia de resistencia territorial se registra en los Montes de María, al norte del país, por medio del cineclub itinerante. En el apartado anterior se mostró cómo esta iniciativa buscó dotar al territorio de significados distintos a los de la violencia, acá interesa resaltar la estrategia territorial que se constituye como resistencia, pues el carácter itinerante del cineclub fue un recurso que deslocalizó la iniciativa, al tiempo que rescató los espacios públicos como lugares de encuentro legítimo entre los pobladores. Ese recuperar el sentido del territorio es un tipo de resistencia que la autora denomina política del lugar, entendida como "acciones movilizadas desde prácticas culturales que interpelan, retan y controvierten lógicas homogeneizantes respecto al lugar" (Garzón, 2008: 186).

Tal como lo muestra Oslender (2008) con el concepto de geografia del terror, la violencia se ha inscrito en los lugares, de ahí que algunos autores plantean la necesidad de construir una geografia de la civilidad, de las formas individuales y colectivas, para superar la barbarie de la guerra (Nates, 2016). Una muestra de esto es lo que describen Nates et al. (2017) en su investigación en cuatro municipios de Caldas, donde evidencian que las personas usan la palabra frentear para expresar las estrategias con las cuales le hacen frente al conflicto, pero que esa acción se realiza desde el lugar mismo de los acontecimientos, a diferencia de la categoría de resistencia, que remite más a una iniciativa política y colectiva no necesariamente llevada a cabo desde el lugar.

En suma, las investigaciones expuestas en este apartado dan cuenta de iniciativas de distintas comunidades organizadas que resisten a la violencia y construyen paz, dándole un lugar central al territorio en sus estrategias de lucha, sea porque buscan defenderlo, darle un significado distinto al de la violencia o porque lo quieren salvaguardar por considerar que en él se encuentran elementos de la naturaleza que el Estado, las multinacionales o los grupos armados no abordan en beneficio de todos. 


\section{Impactos y transformaciones territoriales a causa del conflicto armado}

El conflicto armado impone diferentes transformaciones en el territorio -tanto en su dimensión física como simbólica- que se ven reflejadas en cambios en las dinámicas sociales, económicas, culturales y políticas del grupo humano afectado por dicha situación (Aunta; Barrera, 2016; Rico; López, 2017). De esta manera, algunos de los impactos del conflicto en el territorio se derivan directamente del control que ejercen los grupos armados sobre la propiedad de la tierra, sobre lo que se cultiva y lo que no, sobre lo que se permite transportar o a quiénes se les prohíbe transitar, sobre quienes se aceptan en él y quiénes son rechazados (Martín, 2017). Varias de las investigaciones analizadas para este artículo indagaron sobre esas transformaciones en el territorio a causa del conflicto armado, como se puede ver a continuación.

Salas (2016), en su artículo "Conflicto armado y configuración territorial: elementos para la consolidación de la paz en Colombia", señala la persistencia e intensidad de la violencia (acciones bélicas por actores armados) por departamentos, municipios y regiones del país en las últimas décadas. Asimismo, Salas, Wolff y Camelo (2018), en su investigación "Dinámicas territoriales de la violencia y del conflicto armado antes y después del acuerdo de paz con las Farc-Ep", analizan las variaciones de la intensidad del conflicto (comportamiento) en diferentes períodos y espacialidades. Sin embargo, interesa resaltar que más que una configuración territorial, su abordaje se centra en la ubicación geográfica de los actores armados y los hechos violentos por regiones y períodos, con la ayuda de mapas que lo ilustran.

Los análisis de González, Vásquez y Aponte (2017:1) muestran que "el conflicto armado colombiano no se distribuyó homogéneamente espacial y temporalmente; [y] la inserción, asentamiento y expansión de los actores armados no sucede en territorios y espacios vacíos sino que depende de las situaciones específicas de las regiones". Esto, en parte, se explica porque nunca ha habido un control territorial por parte del Estado en varias regiones del país, sino una "presencia diferenciada y desigual de las instituciones y aparatos del Estado en ellas" (González, 2009: 199), y, además, porque algunas zonas de la geografía nacional son selvas o montañas llenas de bosques que fueron origen y refugio de los grupos armados insurgentes durante décadas. Estos autores tratan de explicar que en cada región las relaciones entre actores armados, pobladores, élites e institucionalidad son diversas y que también sufren sus transformaciones en el tiempo y en el espacio.

Por su parte, Mahecha (2016), en su estudio hecho en el departamento del Putumayo, entiende las transformaciones territoriales como los cambios en la estructura socioespacial derivados del modelo de desarrollo capitalista extractivista, y, para entender dichas transformaciones, aborda la forma en la que se relacionan distintos actores: las comunidades (indígenas, campesinos y afrodescendientes), el Estado, las 
empresas transnacionales y los grupos armados ilegales (insurgentes y paraestatales). Es en este entramado, según Mahecha, que se da la producción del espacio en esa dinámica de transformaciones territoriales provocadas por el conflicto armado y la disputa por los recursos naturales.

Lo propio hacen García y Aramburo (2011) en dos regiones del departamento de Antioquia (Urabá y Oriente), donde describen y analizan con profundidad y amplitud las configuraciones territoriales producto de la interacción entre las territorialidades bélicas, las empresariales y las socioculturales, las cuales se superponen con frecuencia (Agnew; Oslender, 2010) y dan cuenta de la realidad dinámica y compleja en la que lo espacial está estrechamente ligado a lo social, poniendo en evidencia la relación permanente entre lo local, lo regional y lo nacional (e incluso lo global). Destacamos aquí el capítulo que, en su libro, las autoras dedican a las reconfiguraciones territoriales derivadas de la expansión paramilitar en el Urabá a finales de la década de 1980, las cuales transformaron las territorialidades establecidas previamente (guerrilleras, empresariales y comunitarias), pues es un nuevo actor que entró a ejercer control militar y social y, con eso, imponer nuevas lógicas de configuración territorial en la región.

En modo similar, González, Gutiérrez, Nieto, Aponte y Rodríguez (2012) explican el fenómeno de la parapolítica a partir del concepto de arena de acción de Ostrom, en donde grupos paramilitares y clase política en el oriente colombiano (Meta y Casanare) intercambian bienes y servicios, cooperan entre sí para alcanzar objetivos comunes y particulares, y se disputan sus posiciones de poder, lo cual impacta las configuraciones territoriales y afecta a las instituciones, las poblaciones e incluso el medio ambiente.

También llama la atención, en el estudio de García y Aramburo (2011), el impacto de los proyectos agroindustriales en la configuración territorial del Urabá antioqueño (plantación extensiva de banano y palma de aceite), que las autoras denominan territorialidades empresariales y que se caracterizaron por una baja regulación del Estado, así como por tener relaciones con los paramilitares que terminaron afectando a líderes sindicales y sociales, además del destierro de una gran parte de la población que terminó desplazada hacia los centros urbanos de la región (territorialidades del acaparamiento), entre otros impactos que, según las autoras, tuvieron su pico más alto de afectación hasta el año 2007. En suma, el trabajo de García y Aramburo (2011) es un análisis territorial con un completo fundamento histórico y cartográfico, uno de los más completos para describir las transformaciones territoriales vinculadas al conflicto armado y la paz en la literatura analizada para este artículo.

En un sentido similar, Narváez (2018) encontró que los cultivos de coca y las consecuentes economías ilegales, el desplazamiento forzado masivo y la concentración 
en la propiedad de la tierra son factores que dan cuenta del impacto del conflicto armado en la región del oriente de Caldas y, para explicar esto, señala que uno de los factores que agudizaron las confrontaciones entre guerrilla y paramilitares fue la creación de un proyecto hidroenergético en la región, lo cual vuelve a vincular el conflicto armado con el actuar de la empresa privada en las transformaciones territoriales y ambientales, como ocurre en otras partes del país (Cuesta, 2018; Mahecha, 2016) y que, incluso, se ha señalado como parte del origen y auge del paramilitarismo en distintas regiones de Colombia (CNMH, 2018; 2020).

Un estudio reveló que las dinámicas del conflicto armado -tipo y presencia de actores armados, de las formas de victimización y de la intensidad del enfrentamiento- tomaron formas distintas en función de los recursos naturales de uso lícito que predominaban en cada región, analizando casos como el café, las flores, el banano, el petróleo y la minería (Rettberg; Leiteritz; Nasi; Prieto, 2018). Se encontró que, en algunos casos,

el control de las rentas generadas por el recurso constituye un motivo principal para explicar la presencia de actores armados en la región (...) [en otros casos] el control del recurso estudiado o de sus rentas no es un motivo principal de la presencia de tales actores, pero la oportunidad de obtener rentas de los recursos los involucra en las dinámicas de la guerra (...) [y en los demás casos] los recursos se mantienen aislados o "blindados" de las dinámicas de guerra. (Rettberg et al., 2018: 8)

Las zonas más propensas para que su economía legal sea afectada por el conflicto armado suelen ser aquellas que cuentan con una estructura institucional débil, ubicadas en las periferias del país, con informalidad en la propiedad de la tierra y con preexistencia de grupos armados ilegales y presencia histórica del narcotráfico. Este análisis ayuda a comprender las dinámicas territoriales del conflicto armado yendo más allá del narcotráfico y otras economías ilegales que predominan en los estudios sobre este conflicto en las regiones del país (Ulloa; Coronado, 2016).

Otros impactos del conflicto armado que tienen que ver con aspectos como lo económico y ambiental son la deforestación y la minería ilegal en la Amazonia (Cuesta, 2018), y el cultivo de coca en regiones donde las posibilidades de comercializar otro producto son escasas (Narváez, 2018), lo cual se da en contextos donde la guerrilla logró posicionar su poder en el territorio a nivel social, económico y político (Vázquez, 2014). Al imponerle al campesino la siembre de coca, se altera su relación con la tierra, pasa de unas prácticas territoriales asociadas al cultivo de distintos alimentos que implicaban un estilo de vida, a una relación instrumental con el de este producto (Ocampo et al., 2017), por eso se habla de una desterritorialización sin desplazamiento, pues se les imponen a los campesinos unas nuevas lógicas territoria- 
les sin la necesidad de que se desplacen. Muchos de estos elementos siguen vigentes en varias regiones del país donde la violencia no desapareció después del acuerdo de paz con las FARC-EP, en la medida en que actores armados al margen de la ley, como la guerrilla del Ejército de Liberación Nacional (ELN) las FARC y de las estructuras organizadas como el Clan del Golfo ${ }^{8}$, han copado los espacios dejados por la extinta guerrilla de las FARC-EP (Salas; Wolff; Camelo, 2018).

Una de las transformaciones del territorio a partir del conflicto es la desterritorialización impuesta (Haesbaert, 2013; Nates, 2011) que se ha dado principalmente hacia campesinos, afrodescendientes e indígenas (Ocampo et al., 2017), pues las confrontaciones entre grupos armados se han hecho principalmente en el campo y en la selva, trayendo como consecuencia el abandono de tierras y acumulación de la propiedad en algunos casos (Narváez, 2018). En este sentido, se transforma el territorio abandonado por sus habitantes a causa de la violencia, pero también cambia el territorio urbano al cual llegan los desplazados, pues allí deben territorializar ese espacio nuevo para ellos, la mayoría de las veces mediado por experiencias de marginación y pobreza; empero, también por redes de apoyo y solidaridad que en ocasiones facilitan esa territorialización del espacio urbano de destino (Motta, 2009).

Por su parte, el estudio de Garzón (2011) aborda el proceso de retorno de una comunidad que fue desarraigada ${ }^{9}$ de su territorio algunos años antes, lo que implica reterritorializar en medio de los fantasmas de la violencia vivida en ese mismo espacio y de la memoria de la vida previa construida allí, sumado a nuevas dinámicas económicas, sociales e institucionales que produce el territorio luego del retorno. De este modo, se puede ver cómo la guerra transforma al territorio, cuando obliga a sus pobladores a abandonar sus tierras, lo cual implica un proceso de desterritorialización que, simultáneamente, conlleva otro de territorialización en los distintos lugares de destino (Haesbaert, 2013), pero las transformaciones territoriales también se dan cuando las poblaciones tienen la oportunidad de regresar a sus tierras. En otras palabras, ni las personas ni el lugar de origen son los mismos luego de la experiencia violenta de desplazamiento, por eso el proceso de territorializar su antiguo espacio implica un vínculo con lo vivido allí anteriormente, pero involucra nuevas dinámicas sociales para reapropiarlo o reterritorializarlo.

7. Es la segunda guerrilla del país, después de las FARC, y con ella no se ha podido consolidar aún una salida negociada al conflicto.

8. Grupo residual de los paramilitares que se desmovilizaron en el año 2007.

9. La autora prefiere este concepto al de desplazado porque considera que hablando de desarraigo se refleja mejor el corte abrupto con los vínculos simbólicos, vitales y afectivos de las personas con su territorio de origen. 
Rico y Escobar (2020) describen la reconfiguración social del territorio como el producto de la experiencia de reincorporación de excombatientes de la guerrilla en la región del Caribe colombiano. En el pasado, transitaban como guerrilleros, ejerciendo control territorial y abasteciéndose de insumos para regresar a las zonas de refugio y confrontación armada, pero en la actualidad habitan el mismo espacio como personas desarmadas, sin camuflados, lo cual implica una relación diferente con los pobladores locales, ya no desde la distancia y verticalidad que implicaba ser parte de un ejército que imponía un control desde las armas, sino desde la horizontalidad de pertenecer y proyectarse con otros en un mismo territorio.

Al disponer de un espacio físico en el cual los exguerrilleros iniciaron sus proyectos en la vida civil, se desarrollaron procesos de organización social, de infraestructura física y de productividad económica por parte de los excombatientes con el apoyo de organizaciones de la sociedad civil, de la cooperación internacional y del Estado, para configurar el territorio en la nueva realidad de la reincorporación en el posacuerdo. Rico y Escobar (2020) plantean que la experiencia previa de organización social y trabajo cooperativo de los exguerrilleros han permitido converger en procesos de resistencia territorial con otros pobladores de la región, para oponerse, por las vías legales y pacíficas, a iniciativas de minería a gran escala que consideran nocivas para el ambiente y su población. Estos son reconocidos como iniciativas para construir territorialidades a favor de la reconciliación social, y aportan nuevos sentidos de pertenencia compartidos entre quienes en el pasado tuvieron una relación enmarcada en el conflicto armado. No obstante, estos procesos están amenazados por las dificultades e incumplimientos del Gobierno nacional en la implementación de los acuerdos de paz, y por el asesinato de líderes sociales y firmantes de paz que no ha cesado hasta el momento, a más de dos años de la firma.

En este orden de ideas, los impactos y las transformaciones territoriales derivadas del conflicto armado descritas aquí muestran que la guerra tiene expresiones diversas según las características geográficas, históricas, políticas, económicas y sociales de cada región; al tiempo que se evidencia que los grupos armados, las élites o grupos empresariales, la institucionalidad estatal y las comunidades locales cuentan con sus respectivas territorialidades que han entrado en conflicto, siendo estas últimas las más afectadas.

Pese a ser las más vulnerables, se han documentado experiencias en las que algunas comunidades han logrado incidir en la construcción del territorio con procesos de organización social, resistencia y dignidad que les han permitido salvaguardar sus estilos de vida, sus saberes y formas de territorializar que la guerra les ha querido arrebatar durante años. Las iniciativas de paz y reconciliación han transformado territorios en el país, pero han sido poco visibles, por lo cual es un deber de la ciudadanía 
y de la academia potencializar las territorialidades no violentas que se están dando como parte del conjunto de medidas necesarias para dejar la guerra en el pasado.

\section{La gestión territorial en los estudios sobre conflicto y paz}

En este apartado, se analizan las investigaciones que abordan la gestión territorial con relación al conflicto armado y la paz en Colombia. En este sentido, investigadores como González (2009) y Posada, Campuzano y Berrocal (2017) entienden la gestión territorial como la suma del trabajo desarrollado por diversos actores sociales, mediados por interacciones en un espacio determinado, con el fin de dinamizar un futuro más prometedor de sus interesados a través de proyectos, programas y estrategias de acción; es decir, estos autores consideran que la gestión territorial debe ser mediada por la asociatividad y procesos de gobernanza territorial ${ }^{10}$. También se entiende que la gestión territorial, además de los elementos anteriormente expuestos, debe centrarse en actividades de planificación y ordenamiento territorial como la organización y división del territorio (Massiris, 1999; Posada et al., 2017).

Interesa resaltar aquí los estudios que abordan reflexiones sobre la gestión territorial en contextos del conflicto armado y el posconflicto. Algunos autores consideran que, en la actualidad, la gestión territorial en Colombia debe estar orientada a los desafíos que representa la implementación de los acuerdos de paz firmados entre el Gobierno colombiano y la guerrilla de las FARC-EP (Calderón; Garzón, 2018; Tuirán; Trejos 2017; Vásquez, 2014; Villegas; Díaz; Nieto, 2017), al tiempo que señalan que la estructura institucional actual del país no está preparada para esos nuevos desafíos. Por lo tanto, se hace necesario realizar algunas reformas en sus diferentes escalas, teniendo en cuenta la territorialización de las acciones del Estado y la comprensión de las formas de territorialización de las víctimas del conflicto armado.

Es importante resaltar la manera como el conflicto armado ha sido históricamente una de las principales barreras para la consolidación de una gestión territorial como herramienta para el adecuado diseño de las políticas públicas en Colombia. Una de las causas históricas del conflicto armado es la desterritorialización, a partir de prácticas violentas como el despojo que deriva en la concentración de la propiedad de las tierras ${ }^{11}$ por parte de algunas élites regionales y nacionales que, además, controlan las políticas del Estado para su propio beneficio (Ávila, 2019), lo cual dificulta que la gestión territorial cumpla su propósito como herramienta para la construcción de

10. Farinós (2008) define la gobernanza territorial como la forma de territorializar el espacio de acuerdo con las visiones, deseos e intereses de sus agentes.

11. Harvey (2005) analiza este mismo fenómeno a una escala histórica y global en la sociedad capitalista a partir de su concepto de acumulación por desposesión. 
bienestar colectivo y justicia social en los territorios, incluso ahora, en el marco del posacuerdo (CNMH, 2016; Vallejo; Zamora; Sacher, 2019).

Para la época que estuvo abierta la mesa de negociación en La Habana, entre el Gobierno de Colombia y las FARC-EP (2012-2016), se pudo evidenciar, en algunas publicaciones, un tono de expectativa frente a lo que sería la implementación en términos de reformas y adecuación del modelo de ordenamiento territorial, así como la organización territorial vigente en ese momento, lo cual implicaba la necesaria participación activa de las distintas expresiones sociales y comunitarias (Barrera, 2015; Flórez; Rodríguez, 2016; Maldonado, 2016; Rojas, 2016; Salcedo, 2015). Así, la mayoría alerta sobre los desafíos de la implementación de los acuerdos, frente a la necesidad de saldar deudas históricas referidas a la falta de confianza en las instituciones del Estado (Barrera, 2015) y la importancia de reducir la desigualdad entre el campo y la ciudad (Pfeiffer, 2015), para que la paz logre ser una realidad tangible. Una vez firmados los acuerdos de paz, en el año 2016, los académicos pasaron a un discurso crítico frente a lo que fueron descubriendo sobre su implementación en los diferentes puntos: una gran distancia entre lo acordado y las realidades de las comunidades en las regiones del país (Bedoya, 2019; Cairo et al., 2018; García; López; Montealegre; Ocampo; Vargas, 2017; Marín; Espinosa, 2017).

En este sentido, García et al. (2017) analizaron el componente rural y agrario de los acuerdos de paz (con base en informes de la Fundación Paz y Reconciliación) y establecieron que, a un año de su firma, los avances en términos de implementación presentaban importantes limitaciones. En el mismo sentido, Bedoya (2019) realizó un análisis histórico del desarrollo normativo que ha tenido el país para atender los requerimientos del sector rural y agrario, y volvió a indicar las falencias de la implementación del primer punto de los acuerdos de paz (reforma rural integral), esta vez a tres años de su firma. Este mismo autor extendió su crítica a la ley que promovía las Zonas de Interés de Desarrollo Rural, Económico y Social (ZIDRES), pues señalaba que esta ley contenía acciones como el arriendo de baldíos para actividades de agroindustria, situación que ponía en desventaja a los campesinos que no contaban con el capital económico para competir con las grandes empresas, por lo cual, aunque la ley promoviera la incorporación de pequeños campesinos a través de algunos incentivos, la propuesta se desarrollaba en un escenario de asimetría.

De acuerdo con lo anterior, se establece que uno de los principales retos para consolidar una política agraria en Colombia, en perspectiva del posconflicto, debe pasar por tres líneas de acción: 1) reconfigurar el modelo que ponga en el centro de atención a los campesinos, jóvenes y mujeres rurales; 2) repensar la ocupación y el uso del territorio a partir de un nuevo reordenamiento del mismo; y 3) revisar la estructura de la tenencia de la tierra desde un enfoque de desarrollo humano y 
equidad. En este sentido, la gestión territorial deberá jugar un papel preponderante en la territorialización de los acuerdos de paz y el fortalecimiento de las capacidades locales de las entidades territoriales como los municipios y departamentos (Borja, 2017; Tuirán; Trejos, 2017). Además, se destaca, cada vez con mayor fuerza, la idea de que las políticas públicas para la gestión territorial deben construirse desde las bases sociales, especialmente con la participación de las comunidades campesinas y minorías étnicas, quienes han sido históricamente las más afectadas por el conflicto armado (Barrera, 2015; Calderón; Garzón, 2018; Madridejos; Salinas, 2018; Maldonado, 2016; Villegas, 2017; Villegas et al., 2017).

Justamente, el componente de participación social en la implementación de los acuerdos de paz fue lo que suscitó un debate en el mundo académico frente al concepto de paz territorial. Este concepto se comenzó a difundir a partir del año 2014, desde los documentos oficiales del Gobierno colombiano y a través de los discursos del alto comisionado para la paz (Jaramillo, 2014), en medio de las negociaciones con la guerrilla de las FARC-EP. El concepto de paz territorial, si bien es ampliamente difundido y acogido por algunas organizaciones y académicos (Barrera, 2015; Maldonado, 2016; Ríos; Gago, 2018), es difuso, impreciso y polisémico (Cairo et al., 2018; Cairo; Ríos, 2019), y tiende a relacionarse con un enfoque que aboga por la consolidación de la democracia-legitimidad de las instituciones del Estado y mecanismos de participación ciudadana- en regiones periféricas, donde tradicionalmente no ha existido nunca o no existe, como consecuencia de la guerra.

Sin embargo, la idea de paz territorial es criticada porque se limita a asumir el territorio como un contenedor que hay que llenar, un escenario, un contexto o una unidad administrativa con límites determinados; reduce la paz a la presencia de las instituciones del Estado y del mercado en las regiones que han sido afectadas por el conflicto (Cairo et al., 2018); privilegia lo externo sobre los intereses de los locales, es decir, es vertical porque asume la participación de las comunidades solo como forma de legitimar lo que se les impone, y considera que solo hay unos actores violentos que han vulnerado los derechos de las comunidades, los actores ilegales, dejando de lado que, no en pocos casos, hay regiones en donde el mismo Estado o miembros del sector productivo han sido actores del conflicto involucrados en casos de violación de derechos humanos (Bautista, 2017).

Por lo anterior, algunos autores abogan por pensar tanto el conflicto como la paz -desde lo territorial- como una construcción geosociohistórica (no como contenedor), es decir que para construir paz hay que entender primero cómo el conflicto creó territorio, dejar de verlo como un agente pasivo que hay que vaciar de una cosa para llenarlo con otra (Bautista, 2017; Courtheyn, 2019; Peña, 2019); esto es, reconocer las territorialidades del conflicto en un complejo entramado de relaciones de poder 
entre distintos actores, a partir de una lectura multiescalar y multidimensional del territorio, poniendo en el centro las importantes experiencias y sentidos de paz que han tenido las comunidades, y de las cuales hay que aprender para territorializar la paz (Peña, 2019), pues solo así se pueden llegar a promover nuevas territorialidades no violentas. Las estrategias para la paz territorial deben partir de reconocer que la guerrilla tuvo una legitimidad social en zonas donde actuó históricamente, pero en otras, donde actuó por un tiempo más corto y su presencia fue principalmente coercitiva, probablemente cuentan con un rechazo social que es un obstáculo adicional a la construcción de paz (González et al., 2017; Cairo et al., 2018).

Lo anterior plantea una discusión sobre la paz territorial desde la justicia social y espacial (Jiménez-Martín, 2016), que implica un ordenamiento del territorio culturalmente inclusivo, socialmente equitativo y ambientalmente justo (Cairo et al., 2018). Esto supone reconocer las formas en que el conflicto afectó a cada región, y hace visible el papel de los actores no armados en las distintas escalas, tanto en el conflicto como en las posibilidades de construir la paz. Es por esto que Nates et al. (2017) llaman la atención sobre la necesidad de pensar lo local en lo rural, desde el sentido de lugar (de la casa, la finca y la vereda) para las víctimas del campo, con el objetivo de lograr una real reparación y justicia territorial, esto sería "la territorialización más eficaz al momento de hablar de instaurar en el campo los posacuerdos" (Nates et al., 2017: 76).

De una forma ciertamente irónica, las organizaciones sociales que fueron críticas de la noción inicial de paz territorial, luego han sido las que más han defendido y exigido la implementación de los acuerdos de paz, ante los incumplimientos de los dos gobiernos que la han tenido a cargo desde la firma hasta la actualidad ${ }^{12}$, entendiendo que, si bien no comparten su concepción totalmente, sería un avance en sus luchas históricas y los acercaría a su idea de paz con justicia social y territorial mucho más de lo que lo hace la institucionalidad del país sin el acuerdo de paz. Por lo anterior, en un análisis crítico de la noción de paz territorial realizado por destacados expertos en el tema (Cairo et al., 2018), se concluye que "es importante abordar lo territorial de manera que reconozca las relaciones multi-direccionales entre espacio, política y sociedad, para que las estrategias definidas en los Acuerdos de Paz se implementen en un contexto de procesos geo-históricos concretos" (Cairo et al., 2018: 485).

Según esto, el conflicto armado a lo largo de cinco décadas obstaculizó el diseño y desarrollo de políticas públicas para la gestión territorial, principalmente en la

12. Se habla del gobierno de Santos, encargado de la implementación de los acuerdos desde que se firmaron hasta el 2018, y del de Duque, quien ha estado encargado de la implementación desde ese año hasta el presente. 
zona rural del país, donde el conflicto se ha sentido con mayor rigor; sin embargo, en el período de posconflicto, la gestión territorial emerge como una herramienta clave para el proceso de territorialización de la paz, poniendo en el centro la participación amplia de toda la ciudadanía, en especial aquella mayormente afectada por el conflicto armado.

\section{Conclusiones}

El año 2016 marcó un hito en la producción de conocimiento sobre los temas de conflicto y paz en el país, a raíz de las expectativas que creó el proceso de paz con la guerrilla de las FARC-EP, lo cual se evidencia en el incremento de publicaciones sobre el tema, incluyendo estudios con enfoque territorial, como los que se analizaron en este artículo. Justamente, es este enfoque el que les permitió a los académicos encender las alarmas sobre la manera como se han venido dando los procesos de implementación de los acuerdos de paz, en especial en lo referido a su primer punto sobre reforma rural íntegra y los obstáculos que enfrenta la paz territorial que tanto se plantea en ellos.

En el plano metodológico, si bien hay algunos elementos que se expusieron en este artículo acerca de ciertos métodos y técnicas específicos para el estudio del conflicto y la paz, se evidencia un vacío en este aspecto, por lo cual sería importante que más investigadores se interesen en desarrollar reflexiones teórico-metodológicas desde lo territorial para consolidar este campo de conocimiento y, así, brindar mayores herramientas a los nuevos investigadores que buscan entender cómo desarrollar sus trabajos empíricos desde esta perspectiva.

Una cantidad importante de estudios sobre el territorio en contextos de conflicto armado se ocupa de la dimensión simbólica en cuanto a representaciones, imaginarios o valores que le asignan distintos tipos de poblaciones a su espacio, aspectos que, en algunos casos, se vinculan con su identidad colectiva y con procesos de territorialización y reterritorialización, en especial en poblaciones afectadas por el desplazamiento forzado. Algunas comunidades organizadas han realizado acciones encaminadas a resignificar sus territorios para desligarlos del sentido de dolor y sufrimiento que dejan los hechos violentos, y empezar a dotarlos de un nuevo sentido más asociado a la sobrevivencia, a la dignificación de sus víctimas a través de la memoria, y a la acción social solidaria y no violenta, de ahí que muchas veces se reconozcan como comunidades o territorios de paz. Es por esto que varios estudios se ocupan de conocer las distintas formas de resistencias territoriales que han surgido desde las mismas comunidades víctimas del conflicto armado, las cuales 
buscan defender sus territorios no solo de los violentos, sino también de proyectos impulsados por la empresa privada y el Estado que representan grandes riesgos para esas comunidades ambiental, económica y socioculturalmente.

También existe un grupo de investigaciones que se ha ocupado de estudiar las distintas transformaciones producidas en los territorios como consecuencia directa del conflicto armado, por la forma como se ha dado la interacción a lo largo del tiempo entre las comunidades, los grupos armados, los empresarios o terratenientes y agentes del Estado. De la interacción entre esos actores se ha derivado una serie de impactos en los territorios, tanto en lo físico-ambiental como en lo económico-productivo, que se evidencia en la concentración de la tenencia de la tierra y dinámicas sociales como el despojo y la concentración de la población desplazada en las márgenes de los centros urbanos.

Por último, se han referido en este artículo investigaciones que se han ocupado de abordar los desafíos de la gestión territorial en el marco del posconflicto en Colombia, lo cual implica, de una parte, la participación ciudadana en el diseño de las políticas públicas para los territorios y, de otra, la revisión de la estructura de la organización territorial en las distintas escalas del Estado. Sin embargo, esto debería ir acompañado de una comprensión del territorio como una construcción geosociohistórica que permita analizar las relaciones de las territorialidades de distintos actores clave en el marco del conflicto, a partir de una lectura multidimensional y multiescalar del territorio que aporte al diseño de políticas sociales más pertinentes $y$, de ese modo, a la creación de territorialidades no violentas en un momento del país donde la guerra puede volver a escalar y recrudecerse (como está ocurriendo en algunas regiones).

Con base en la anterior revisión de la literatura sobre conflicto armado y construcción de paz en Colombia desde una perspectiva territorial, se puede afirmar que el principal desafío que tienen los investigadores en la materia es tratar de realizar estudios sociales en zonas donde el conflicto continúa en manos de otros actores armados ilegales que han buscado aprovechar el vacío que dejaron las FARC; pero también lograr establecer lógicas de comprensión territorial de la vida de otras comunidades que sí están viviendo un verdadero posconflicto porque ya no experimentan hechos violentos. Esto significa que la academia y los estudios territoriales deben estar preparados para comprender los desafíos que presenta la compleja realidad colombiana actual, y aportar a que el esfuerzo institucional y social que se invirtió en las negociaciones y en el acuerdo de paz con las FARC no se pierdan y se logre construir una sociedad que pueda tramitar sus diferencias de formas no violentas, para, de este modo, contribuir a la justicia social y territorial que ha estado tan en mora en nuestro país. 


\section{Referencias}

Agnew, John; Oslender, Ulrich (2010). Territorialidades superpuestas, soberanía en disputa: lecciones empíricas desde América Latina. Tabula Rasa, 13, 191-213.

Aria, Massimo; Cuccurullo, Corrado (2017). Bibliometrix: An R-Tool for Comprehensive Science Mapping Analysis. Journal of Informetrics, 11(4), 959-975.

Aunta, Andrés; Barrera, Víctor (2016). Conflictividades y agendas territoriales. Bogotá: Red PRODEPAZ.

Ávila, Ariel (2019). Detrás de la guerra en Colombia. Bogotá: Planeta.

Barrera, Víctor (2015). Sociedad civil y paz territorial. Aprendizaje social, movilización ciudadana y gobernabilidad local. En Estrategias para la construcción de paz territorial en Colombia. Elementos para la discusión (pp. 62-87), editado por Fernán González; Tania Guzmán; Víctor Barrera. Bogotá: CINEP/PPP.

Bautista, Sandra Carolina (2017). Contribuciones a la fundamentación conceptual de la paz territorial. Ciudad Paz-Ando, 10(1), 100-110. https://doi.org/10.14483/2422278x.11639

Bedoya, María Rocío (2019). Luces y sombras en la implementación del acuerdo de tierras en Colombia. Estudios Políticos, 54, 37-58.

Borja, Miguel (2017). Perspectivas territoriales del acuerdo de Paz. Análisis Político, 30(90), 61-76.

Cairo, Heriberto (2013). Espacio y política: por una teoría política situada. Dados, 56(4), 769802.

Cairo, Heriberto; Oslender, Ulrich; Piazzini, Carlo Emilio; Ríos, Jerónimo; Koopman, Sara; Montoya, Vladimir...; Quintero, Zambrano (2018). "Territorial Peace”: The Emergence of a Concept in Colombia's Peace Negotiations. Geopolitics, 23(2), 464-488. https://doi.or $\mathrm{g} / 10.1080 / 14650045.2018 .1425110$

Cairo, Heriberto; Ríos, Jerónimo (2019). Las élites políticas y la paz territorial en Colombia: un análisis de discurso en torno al Acuerdo de Paz. Revista Española de Ciencias Políticas, 50, 91-113. https://doi.org/10.21308/recp.50.04

Calderón, Dulfary; Garzón, Lorena (2018). Territorialización en el posconflicto: perspectivas para la implementación de políticas. Estudios de Políticas Públicas, 4(1), 63-78.

Capel, Horacio (2016). Las ciencias sociales y el estudio del territorio. Revista Bibliográfica de Geografia y Ciencias Sociales, 21(1149), 1-38. Recuperado de http://www.ub.edu/geocrit/ b3w-1149.pdf

Centro Nacional de Memoria Histórica (2015). Memoria, territorio y luch a campesina. Aportes metodológicos para la caracterización del sujeto y el daño colectivo con población campesina 
en la región caribe desde la perspectiva de memoria histórica (Documento de trabajo). Bogotá: CNMH.

Centro Nacional de Memoria Histórica (2016). Tierras y conflictos rurales: historia, políticas agrarias y protagonistas. Bogotá: CNMH.

Centro Nacional de Memoria Histórica (2018). Paramilitarismo. Balance de la contribución del CNMH al esclarecimiento histórico. Bogotá: $\mathrm{CNMH}$.

Centro Nacional de Memoria Histótica (2020). Isaza, el clan paramilitar. Las autodefensas campesinas del Magdalena Medio. Bogotá: CNMH.

Chávez, Yuri; Ramírez, María (2018). Representaciones sociales sobre el territorio, desde los acuerdos de La Habana, en un grupo de mujeres rurales del municipio de Viotá, Cundinamarca. Tabula Rasa, 29, 295-314. https://doi.org/10.25058/20112742.n29.14

Coser, Lewis A. (1970). Nuevos aportes a la teoría del conflicto. Buenos Aires: Amorrortu.

Courtheyn, Christopher (2019). Territorios de paz: otras territorialidades en la Comunidad de Paz de San José de Apartadó, Colombia. Territorios, 40, 291-318.

Cuesta, Óscar (2018). Trabajos sobre indígenas y territorio en Colombia, estado de la cuestión. Revista Latina de Sociología, 8(3), 61-75.

Echandía, Camilo; Cabrera, Irene (2017). Madurez para la paz: evaluación de la territorialidad y las estrategias en el conflicto colombiano. Bogotá: Universidad del Externado.

Escobar, Arturo (2015). Territorios de diferencia: la ontología política de los "derechos al territorio". Cuadernos de Antropología Social, 41, 25-38.

Espinosa, Nicolás; González, Eugenia; Ramírez, Érika (2012). Etnografía, territorio y conflicto armado. Metodología de una investigación sobre la construcción regional de los Llanos del Yarí (Caquetá, Colombia). Ágora USB, 12(2), 329-348.

Farinós, Joaquín (2008). Gobernanza territorial para el desarrollo sostenible: estado de la cuestión y agenda. Boletín de la Asociación de Geógrafos Españoles, 46, 11-32.

Flórez, David; Rodríguez, Javier (2016). Ordenamiento territorial en Colombia: violencias, guerra y resistencias. Bitácora Urbano-Territorial, 26(2), 37-44.

Galtung, Johan (1969). Violence, Peace and Peace Research. Journal of Peace Research, 6(3), 167-191.

García, Gisel; López, Juan Camilo; Montealegre, Carlos; Ocampo, Kler Valentina; Vargas, Karen (2017). Políticas públicas y paz territorial: perspectivas sobre la incidencia de la comunidad internacional a partir de los puntos 1 y 2 de los acuerdos de La Habana en el norte del Cauca 2016-2017. Perspectivas Internacionales, 12(2), 65-91. 
García de la Torre, Clara Inés; Aramburo-Siegert, Clara Inés (eds.), (2011). Geografías de la guerra, el poder y la resistencia. Oriente y Urabá Antioqueños. 1990-2008. Bogotá/Medellín: CINEP/ODECOFI/INER.

Garzón, Angélica María (2008). Retando las geografías de terror: estrategias culturales para la construcción del lugar. Nómadas, 28, 183-193.

Garzón, Angélica María (2011). Andar los recuerdos: elementos para pensar el territorio desde los procesos de retorno de población desarraigada por la violencia. Encuentros, 1, 83-94.

González, Fernán (2009). Espacio, conflicto y poder: las dimensiones territoriales de la violencia y la construcción del Estado en Colombia. Sociedad y Economía, 17, 185-214.

González, Fernán; Gutiérrez-Lemus, Omar Jaime; Nieto-Matiz, Camilo; Aponte-González, Andrés Felipe; Rodríguez-Cuadros, José Darío (2012). Conflicto y territorio en el oriente colombiano. Bogotá: ODECOFE/CINEP.

González, Fernán; Vásquez, Teófilo; Aponte, Andrés (2017). Acercamiento a la evolución territorial de los actores armados: sugerencias para la construcción de la paz territorial. En La paz en el territorio, poder localy posconflicto en Colombia (pp. 69-148). Bogotá: Universidad Externado de Colombia.

Haesbaert, Rogério (2013). Del mito de la desterritorialización a la multiterritorialidad. Cultura y Representaciones Sociales, 15, 9-42.

Harvey, David (2005). El "Nuevo" imperialismo: acumulación por desposesión. En Registro socialista (pp. 99-129). Buenos Aires: CLACSO.

Jaramillo, Sergio (2014). La paz territorial. Conferencia presentada en Universidad de Harvard, Cambridge, Estados Unidos. Recuperado de https://interaktive-demokratie.org/files/ downloads/La-Paz-Territorial.pdf

Jiménez-Martín, Carolina (2016). Justicia territorial para la construcción de la paz. Bitácora Urbano-Territorial, 26(2), 59-66. https://doi.org/10.15446/bitacora.v26n2.59301

Lederach, Jean Paul (2000). El abecé de la pazy los conflictos. Madrid: Los libros de la Catarata.

Lizarralde, Mauricio (2012). Ambientes educativos y territorios del miedo en medio del conflicto armado: estudio sobre escuelas del Bajo y Medio Putumayo. Revista Colombiana de Educación, 62, 21-39.

Llanos, Luis (2010). Concepto de territorio y las investigaciones en las ciencias sociales. Agricultura, Sociedad y Desarrollo, 7(3), 207-220.

Madridejos, Carlos; Salinas, Yolanda (2018). Nuevos territorios de paz. Aportes y recomendaciones para la territorialización de los acuerdos y la implementación de la reforma rural integral. Opera, 22, 5-27. 
Mahecha, Camilo (2016). Transformaciones territoriales: una categoría para explicar las dinámicas de conformación territorial. Bitácora Urbano-Territorial, 2, 113-120.

Maldonado, Diego Fernando (2016). La participación ciudadana en la construcción de paz territorial en Colombia. En Construcción de desarrollo y paz: aprendizajesy recomendaciones desde los territorios (pp. 109-125). Bogotá: CINEP.

Marín, Karen; Espinosa, Nicolás (2017). Normalización sin transición: la dimensión territorial del proceso de paz en la Zona Veredal de Transición y Normalización (ZVTN) de la Macarena. Ágora USB, 17(2), 441-461.

Martín, Luis (2017). Dinámica de la guerra en el control institucional del territorio en Colombia. En El control territorial en el siglo XXI: fundamentos teóricos (pp. 169-223). Bogotá: Escuela Superior de Guerra.

Massiris, Ángel (1999). Ordenamiento territorial: experiencias internacionales y desarrollos conceptuales y legales realizados en Colombia. Perspectiva Geográfica, 4, 1-48.

Monnet, Jerome (2013). El territorio reticular. En Enfoquesy métodos en los estudios territoriales (pp. 137-167), compilado por Beatriz Nates. Manizales: Universidad de Caldas.

Motta, Nancy (2009). Las nuevas tribus urbanas de Cali. Desplazamiento forzado desterritorialización y reterritorialización. HiSTOReLo, 1(2), 32-85.

Muñoz, Francisco; Bolaños, Manuel Jorge (2011). La praxis (teoría y práctica) de la paz imperfecta. En Los hábitus de la paz: teorías y prácticas de la paz imperfecta (pp. 13-36), coordinado por Francisco Muñoz; Manuel Bolaños. Granada: Universidad de Granada.

Narváez, Diego (2018). El conflicto armado como factor de transformación territorial del Oriente de Caldas, Colombia. Civilizar: Ciencias Socialesy Humanas, 18(35), 13-24. https:// doi.org/http://dx.doi.org/10.22518/usergioa/jour/ccsh/2018.2/a02

Nates, Béatriz (2011). Soportes teóricos de conceptos de territorio. Co-Herencia, 8, 209-229.

Nates, Béatriz (2016). Geografías de la civilidad: prácticas y discursos territoriales en escenarios de postconflicto en Colombia. Psicología desde el Caribe, 33(1), 81-96.

Nates, Béatriz; Raymond, Stéphanie (2006). Cartografía semiótica para la comprensión de territorios de conflicto. Estudios políticos, 29, 99-120.

Nates, Béatriz; Velázquez, Paula; García, María (2017). La territorialización de la memoria en escenarios de posconflicto. Caldas 1990-2015. Manizales: Universidad de Caldas.

Ocampo, Myriam; Chenut, Philippe; Férguson, Mayerlin; Martínez, Mabel (2017). Territorialities in Transition: Population Displaced by the Violence of the Colombian Armed Conflict Resignifying the Territory. Psicología USP, 28(2), 165-178. https://doi.org/http://dx.doi. org/10.1590/0103-65642017A001 
Oslender, Ulrich (2008). Geografías del terror: un marco de análisis para el estudio del terror. Scripta Nova, 12(270), 140.

Ospina, David Arturo; López, Sergio; Burgos, Sandra Bibiana; Madera, José Alejandro (2018). La paz entre lo urbano y lo rural: imaginarios de paz de niños y niñas sobre el posconflicto en Colombia. Revista Latinoamericana de Ciencias Sociales, Niñezy Juventud, 16(2), 943-960. https://doi.org/https://doi.org/10.11600/1692715x.16220

Peña, Luis (2019). Paz territorial: conectando imaginación moral e imaginación geográfica. Bogotá: CAPAZ.

Pfeiffer, Silke (2015). Territorial peacebuilding in Colombia: the opportunity to do what has not been achieved before? Norwegian Peacebuilding Resource Centre. Recuperado de https:// www.files.ethz.ch/isn/192284/d6c6acc131e49dbc761018bfe2951621.pdf

Pissoat, Olivier; Gouëset, Vincent (2002). La representación cartográfica de la violencia en las ciencias sociales colombianas. Análisis Politico, 45, 3-34.

Posada, Adriana; Campuzano, Antonio; Berrocal, Ana (2017). Gestión territorial mediante estrategia de asociatividad para Casanare-Colombia. U. D. C. A. Actualidady Divulgación Cientifica, 20(2), 445-456.

Rettberg, Angelika; Leiteritz, Ralf; Nasi, Carlo; Prieto, Juan Diego (2018). ¿Recursos diferentes, conflictos diferentes? Un marco para comprender la economía política del conflicto armado y la criminalidad en las regiones colombianas. Bogotá: Universidad de los Andes. Recuperado de https://www.researchgate.net/publication/326219845_Recursos_diferentes_conflictos_ diferentes_Un_marco_para_comprender_la_economia_politica_del_conflicto_armado_y_la_ criminalidad_en_las_regiones_colombianas

Rico, Diana; Escobar, Fredy (2020). Reconfiguración social del territorio, Serranía del Perijá: reincorporación de colectivos farianos en el posacuerdo. Bogotá: Friedrich Ebert Stiftung.

Rico, Diana; López, Julián (2017). Introducción. En Territorios, conflictosy posconflictos. Miradas transdisciplinares (pp. 1-12). Barranquilla: Universidad del Norte.

Ríos, Jerónimo; Gago, Egoitz (2018). Realidades y desafíos de la paz territorial en Colombia. Papers, 103(2), 281-302. http://dx.doi.org/10.5565/rev/papers.2361

Rojas, Jorge (2016). Posacuerdo y gestión territorial en Colombia. Bitácora Urbano-Territorial, 26(2), 135-146.

Ruiz, Daniel (2017). El territorio como víctima. Ontología política y las leyes de víctimas para comunidades indígenas y negras en Colombia. Revista Colombiana de Antropología, 52(2), 85-113. https://doi.org/10.22380/2539472x.118 
Salas, Luis Gabriel (2016). Conflicto armado y configuración territorial: elementos para la consolidación de la paz en Colombia. Bitácora Urbano-Territorial, 26(2), 45-57. https://doi. org/10.15446/bitacora.v26n2.57605

Salas, Luis Gabriel; Wolff, Jonas; Camelo, Fabián Eduardo (2018). Dinámicas territoriales de la violencia y del conflicto armado antesy después del acuerdo de paz con las FARC-EP. Estudio de caso: municipio de Tumaco, Nariño. Bogotá: Instituto Colombo-Alemán para la Paz (CAPAZ).

Salcedo, Leonardo (2015). Propuestas de paz territorial desde los movimientos sociales: multiculturalismo, ordenamiento territorial y ejemplos de paz territorial. Análisis, 10, 1-16.

Soja, Edward W. (2010). La dialéctica socio-espacial. En La perspectiva postmoderna de un geógrafo radical (pp. 81-109). Barcelona: Icaria/Espacios críticos.

Tamayo, Camilo; Navarro, Daniela (2017). Después de la guerra: otra Medellín. Ciudadanías comunicativas, apropiación urbana y resignificación de espacios públicos en clave de memoria y posconflicto. Signo y Pensamiento, 36(70), 54-73. https://doi.org/10.11144/ Javeriana.syp36-70.dgmc

Tuirán, Ángel; Trejos, Luis (2017). Debilidades institucionales en el nivel local. Desafíos de la gestión territorial de la paz. Análisis Político, 90, 77-102.

Ulloa, Astrid; Coronado, Sergio (eds.), (2016). Extractivismos y posconflicto en Colombia: retos para la paz territorial. Bogotá: CINEP/Universidad Nacional de Colombia.

Uribe, Hernando; Ramírez, Andrés Felipe (2014). Sentidos de lugar y movimiento social: indígenas de Toribío y defensa de su territorio en Colombia. Latinoamérica, 58, 9-31. https:// doi.org/10.1016/s1665-8574(14)70099-7

Vallejo, Ivette; Zamora, Giannina; Sacher, William (2019). Despojo(s), segregación social del espacio y territorios de resistencia en América Latina. Presentación del dossier. Íconos, 64, 11-32.

Vázquez, Teófilo (2014). El papel del conflicto armado en la construcción y diferenciación territorial de la región de "El Caguán”, Amazonía Occidental Colombiana. Ágora USB, $14(1), 147-175$.

Vélez, Irene; Rátiva, Sandra; Varela, Daniel (2012). Cartografía social como metodología participativa y colaborativa. Revista Colombiana de Geografia, 21(2), 59-73.

Villegas, Ernesto (2017). Aplicación de los modelos de gestión territorial a través de las unidades de planificación territorial, “lecciones aprendidas”. Arkitekturax Visión FUA, 1(1), 151-175.

Villegas, Ernesto; Díaz, Aura; Nieto, Lorena (2017). Propuesta del modelo espacial para la evaluación y gestión del territorio, para la incorporación de las Unidades de Planificación y Gestión Territorial (UPGT) al pos-conflicto colombiano. Ágora USB, 17(2), 472-496. 